\title{
Student-identified requirements for persistence in a limited-residency information systems PhD program
}

\author{
Steven R. Terrell, Nova Southeastern University, terrell@nova.edu \\ Michael F. Lohle, The University of Bridgeport, mlohle@bridgeport.edu \\ Donna Kennedy, Indian River Central School District, donnakennedy@ircsd.org
}

\begin{abstract}
The attrition rate for students in traditional doctoral programs hovers around 50\%, while students in limited-residency and online programs tend to leave programs at rates $10 \%$ to $20 \%$ higher. The goal of this study was to better understand this phenomenon from the perspective of graduates of a limited-residency information systems doctoral program. Analysis from interviews with this population yielded a set of best practices, focused primarily on assisting students as they prepared for their dissertation. The development and application of policies, procedures and tools based on results of this research may help administrators, faculty and students address factors that may lead to attrition.
\end{abstract}

Keywords: Persistence, graduate school, limited residency, doctoral

\section{Introduction}

Historically, the attrition rate of doctoral students in traditional, on-campus programs has been $40 \%$ to $50 \%$ (Bowen \& Rudenstine, 1992; National Center for Educational Statistics, 2000; National Research Council, 1996; Smallwood, 2004), while attrition rates for distance-based programs (Rovai, 2002) and specifically, distance-based doctoral programs (Terrell, 2005a), can be as high as $60 \%$ to $70 \%$. In addition to limiting applicants for jobs where doctoral degrees are required, attrition wastes financial and temporal resources of the institution, faculty, and students (Gardner, 2010; Golde, 2005).

Studies have shown that the majority of doctoral students are capable of completing their degrees and many of the barriers that students face pertain to institutional and program characteristics (Bowen \& Rudenstine, 1992; Golde 2005; Lovitts, 2001, 2008), however, the bulk of the research on persistence has focused on traditional doctoral programs. Students in traditional programs are typically fulfilling a research or teaching assistantship while attending school fulltime on campus. In addition, these students tend to be younger, enrolling directly after graduation from a bachelor's or master's program (Holder, 2007). In contrast, the degree program investigated in this study is offered primarily online, requiring students to participate on campus for either two extended weekends or one full week each semester. Typically these students are employed full-time and have family responsibilities, both of which they are balancing with their graduate education. Additionally, students are geographically diverse, with 
none residing on campus and few residing in the immediate area. Given the distinctiveness of the population, it is reasonable to suppose that these students will have different life experiences during their tenure in the program and that their decision to persist will be based on factors not entirely the same as students in a more traditional setting.

\section{Problem Statement}

The attrition rate of students in the information-systems limited-residency doctoral program at the university where the study was conducted is significantly higher (i.e., 60\% to 70\%) than the $50 \%$ attrition rate of students in traditional doctoral programs.

\section{Significance of the Study}

Interest in blended learning is increasing (U.S. Department of Education, 2009) and the number of colleges and universities that offer doctoral programs using a blended learning model is becoming more commonplace. These limited-residency doctoral programs enable working professionals to complete their degrees while at the same time, maintaining their professional careers. Students come to campus for face-to-face instruction a limited number of times during the semester; however, most of the teaching and learning takes place in a virtual environment.

Researchers investigating the causes of attrition from programs such as these have explored the relationship between attrition and funding (e.g., Ehrenberg, Jakubson, Groen, So, \& Price, 2007), student and advisor relationships (e.g., Lovitts \& Nelson, 2000), gender and ethnicity (e.g., Cohoon, Wu, \& Chao, 2009; Gardner, 2008), specific disciplines (e.g., Golde,, 2005; van Ours \& Ridder, 2003), intelligence and learning styles (e.g., , Kennedy et al, 2015, Lovitts, 2008; Terrell, 2002a, 2002b, 2005c, 2014), socialization experiences (e.g., Gardner, 2010, Lovitts \& Nelson, 2000; Terrell, Snyder, Dringus \& Maddrey, 2012) \& neural function (Terrell, 2015). Given the complex nature of an individual's decision to withdraw from a specific program, however, it is challenging to find and understand patterns that might lead to solutions that can be applied across institutions and disciplines (Golde, 2005; van Ours \& Ridder, 2003).

Research surrounding persistence in graduate programs indicates that a variety of factors may influence student persistence. Ivankova and Stick (2007) identified the program, the online environment, faculty, student support services, self-motivation, community, and advising as the seven primary factors that influenced persistence in one distributed doctoral program. However, only intrinsic motivation was found to have a statistically significant effect on student persistence in the program under investigation (Terrell, 2005b). Groen, Jakubson, Ehrenberg, Condie, and Liu (2008) stated that improved financial aid opportunities increased persistence in the program; however, this persistence did not translate into an increase in degree completion.

Gardner (2008) echoes all of these factors as indicative of persistence, but points out that departmental perception of success can influence student persistence and completion. Faculty in departments with high persistence and completion routinely state that self-motivation, selfdiscipline, and an ability to work independently are hallmarks of successful students. Departments with higher than average funding from the institution also displayed higher persistence and completion rates than less well-funded departments at the same institution. Departments with lower persistence and completion rates are less likely to concisely define success, leading Gardner to surmise that an ability to convey terms for success to students may play a role in student persistence and, ultimately, completion. 


\section{Purpose and Research Question}

The purpose of this study was to better understand the lived experiences of students who had graduated from a limited-residency information systems doctoral program. The study was guided by one overarching research question:

What are the factors and experiences you believe contributed to your persistence in a limited-residency doctoral program?

\section{Methodology}

Prior to the onset of this study the researchers applied for and received IRB approval to proceed with the study as described. University personnel were asked to confidentially identify all students who had matriculated from the limited-residency doctoral program between 2010 and 2014 and provide the researchers with a list of possible participants, including their contact information. The researchers sent a recruitment letter along with the informed consent document to solicit participation.

Seven potential participants responded and a mutually agreeable time and date was set for the interviews. At the outset of each interview, the researchers described the purpose and procedures of the study, the risks and benefits, confidentiality and privacy, as well as their right to withdraw from the study at any point. Participants were given an opportunity to ask any questions or share any comments or concerns they may have prior to participation.

Following that, semi-structured interviews were guided by the questions shown in Appendix A. Data saturation was reached after approximately five interviews; because of that, the researchers felt that nothing would be gained from soliciting further participation by other graduates of the information systems program. Each interview was recorded, and transcribed by a professional transcriptionist. Upon completion the transcripts were compared to the original recordings to establish validity.

\section{Identification of Open Codes}

Data analysis began with the open-coding of transcripts. In order to do so, the researcher read each sentence of the transcript and assigned a code reflective of the general ideas underlying the overall phenomenon of the text (Glaser \& Strauss, 1967). These codes represent the highest level of abstraction and allowed the researcher to identify seven axial codes based on one or more common themes within the open codes. The analysis concluded with the development of a selective code tying the axial codes into an overarching theme; this selective code is the source of the best practice emanating from this study. In this case, initial analysis resulted in 150 open codes; during the process of axial coding, seven codes were identified.

\section{Desired Student Characteristics at Matriculation}

While this was one of the least developed codes, persons interviewed described the need for more stringent admissions standards and student characteristics they believed would lead to the success of students entering the program. Examples of comments subsumed under this category are shown in Table 1: 
Table 1 - Desired Student Characteristics

I was completely unprepared for the transition from an MBA practitioner degree to a researchbased Ph.D.

Make sure the student is really ready to go through a life-changing event.

The other part of it is, literally, can you effectively complete a sentence, and a thought and a paragraph.

I'm sure they're (i.e., the admissions office) is looking for bright students to join the program, but are they looking for those who can pursue ideas, who can turn out ideas, pursue ideas, and never quit...something like that on top of just the pure academic record.

One of your goals needs to be defined where is the area of research, you know, you want to focus on.

\section{Reasons for Attending the Chosen University}

When asked why they chose the program, students spoke of personal reasons as well as characteristics of the school. Based on the results of earlier studies conducted within the school (i.e., Terrell, 2005c; Terrell et al, 2012), these were expected (Table 2):

Table 2 - Reasons for Attending

\begin{tabular}{l} 
Table 2 - Reasons for Attending \\
\hline I was interested in going to a school that was an NSA Center of Excellence. \\
\hline I needed to keep working. \\
\hline It's a real school with a real campus with a real reputation. \\
\hline I wasn't sure if I really wanted to leave a career entirely and go into a science PhD. program. \\
\hline I really liked the combination of the limited residency. \\
\hline It's really hard to commit to like a weekly meeting. \\
\hline $\begin{array}{l}\text { I was looking for a SACS accredited program and I was looking for, ideally, something in } \\
\text { information security. }\end{array}$ \\
\hline It provided the least amount of interruption to my work schedule. \\
\hline
\end{tabular}

\section{Students First Impression When Coming to Campus}

The respondents were highly complementary of the faculty, staff, administration and physical resources during their first visit to campus (Table 3). 
Table 3 - First Impression

I was really impressed by the facility...I've never seen a school in such immaculate shape.

I think everyone was also committed to student success.

My first impression was it was a great opportunity..

They had orientation at the time conducted by the Dean, and I thought that was pretty effective. I was impressed in that I found it to be well organized - which was unusual

\section{Coursework}

References to coursework were one of the most pronounced themes emanating from the interviews; comments primarily focused on an appreciation for the coursework and a desire for additional research methodology courses (Table 4):

Table 4 - Coursework

I had great experiences with the coursework.

Coursework, overall it was great. Every professor had his or her own style, and that variety was nice because in some courses, we would be required to write publishable-quality papers, and in other courses it was more of a project work or getting together with others. I think, overall, that creates a fulfilling experience.

I realize that I wanted more research coursework.

In terms of the coursework preparing you for the dissertation, that was really highly varied depending upon (i.e., a given faculty member).

I know for somebody like me who focused on quantitative research, it (i.e., a course in qualitative research methods) would have been invaluable.

I dove right into the qualitative, but, you know, I mean you can't avoid the quantitative. You've got to have that. I don't see how you avoid the qualitative. I guess one thing that I'd love to see because I think life is more mixed methods.

I think the coursework side of it is really, really effective, and I actually commend you all because it was a totally rewarding experience.

I was thinking about my courses and what I wanted to do eventually for dissertation in light of the whole methodology because I've taken statistics in undergrad and grad both, and that was not enough because its research methodology is not just statistics

In terms of the coursework preparing you for the dissertation that was really highly varied.

It (i.e., the research course) wasn't enough for me and, you know, I can say that I struggled quite a bit with trying to understand what was truly expected of me. 


\section{The Dissertation: Preparation and Process}

Problems with preparing for, getting started and writing the dissertation outweighed, by far, all other comments and concerns. Samples of these are shown in Table 5:

Table 5 -Dissertation Preparation

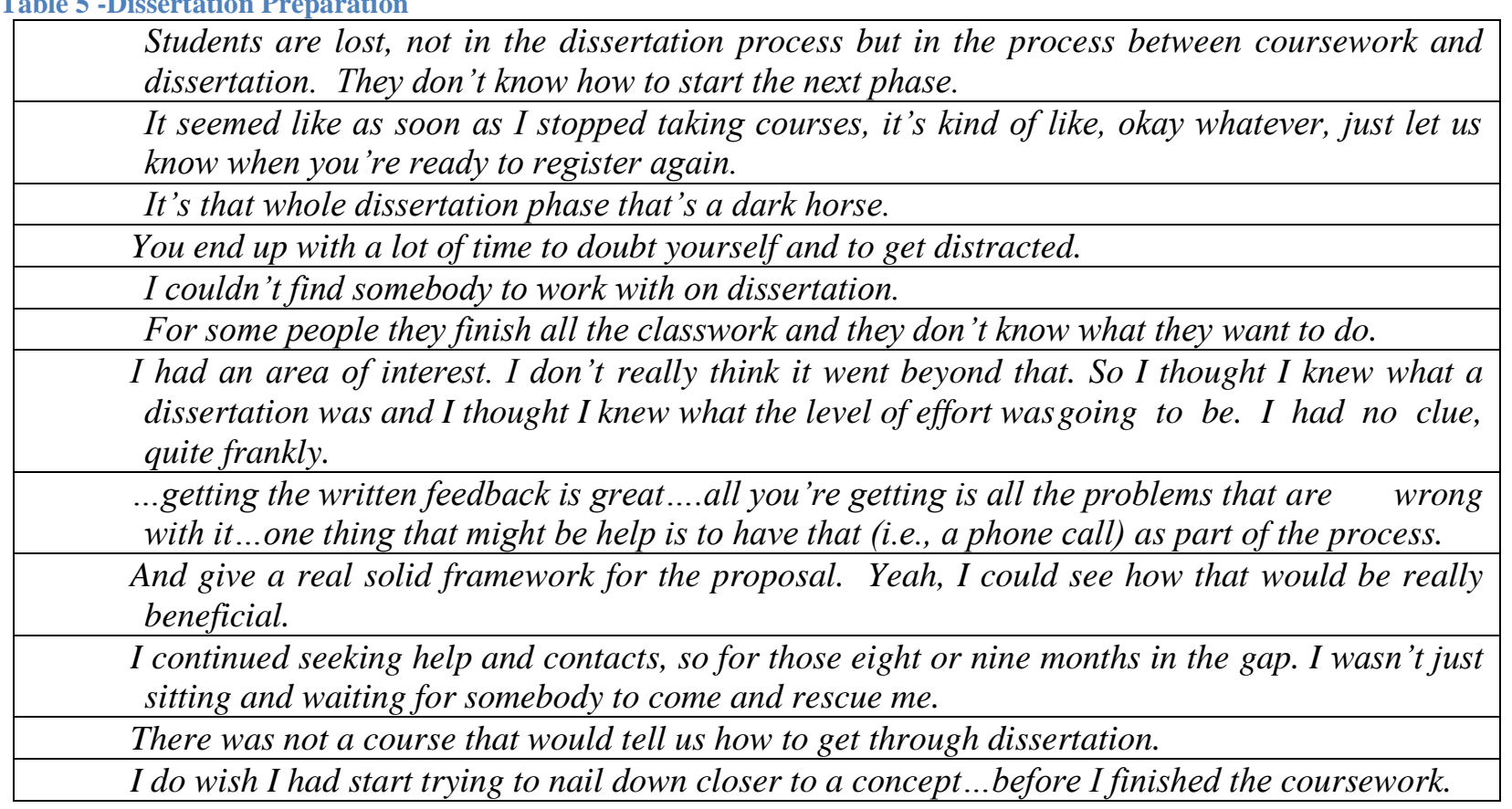

\section{Suggestions for Changes by the College}

While being interviewed, participants offered suggestions for specific changes to the program or administrative process (Table 6):

Table 6 - Suggested Changes to the College

\begin{tabular}{l} 
What would it add if they had an advisor? So they would always know that there's \\
a point of connection there while they were in coursework. \\
Let's have a one-page ... web synopsis of what every faculty member's interests are...that's \\
really going to help many students. \\
$\begin{array}{l}\text { Give a really solid framework for the proposal. Yeah, I could see how that would be really } \\
\text { beneficial. }\end{array}$ \\
$\begin{array}{l}\text { What's truly necessary would be a kind of a program... something that will show students } \\
\text { exactly what they need to do to be ready. }\end{array}$ \\
\hline It (i.e., the doctoral experience) needs to be broken down and operationalized. \\
Just hold a proper orientation and being told things like the first thing you need to do is \\
identify people doing research in the area you're interested in. \\
\hline
\end{tabular}




\section{Advice for Current and Incoming Students}

Graduates of the program were able to retrospectively look back and identify issues they believed would be helpful to students entering the program, as well as for those currently in coursework (Table 7).

Table 7 - Advice for Current and Incoming Students

Pace yourself and start with things that are immediately relevant.

Once you have a potential chair, do not shop your idea around.

Leave your ego at the door and allow yourself to be led a little.

It is not just a mental thing, it's about the way you shift and adapt and change the way you think.

\section{Narrowing the Axial Codes and the Development of Best Practices}

When we examined the axial codes, it was determined that code two (i.e., reasons to attend a limited residency doctoral program) was common to most studies of this type and code three (i.e., the first impression of the program) did not yield, for the most part, information valuable to this investigation; because of that further analysis of the majority of those codes was not conducted. At the same time, items from the sixth code, "Suggestions for Changes by the College", as well as suggestions offered by students in earlier studies with the same population (e.g., Terrell, Snyder, Dringus \& Maddrey, 2012), will be included in each section as appropriate. A complete list or best practices developed from this study are included in Appendix B.

\section{Best Practices for Admission and Initial Entry into the Program}

The first code "i.e., desired student characteristics", did offer valuable insight as the participants reflected upon their personal experience as well as their perception of the needs of other students within the program. First, participants expressed a need that applicants to the program be academically prepared to undertake doctoral studies and, second, they must be aware of the life changes that will likely affect them as they proceed through the program. From this, seven best practices were developed:

1. Applicants should be better screened prior to admission. This may include interviews with faculty members, as well as the use of standardized readiness instruments such as the Graduate Record Exam.

2. Prior to admission, applicants should be counseled as to the differences between the educational experience of a Masters' program and a doctoral program. This should include applicant awareness of the life-style changes, the amount of time that must be dedicated to doctoral study, the reality of attrition, the financial costs, etc.

3. To assist potential applicants in their decision making, the college should provide a page on their web-site for each faculty member that shows detailed information about their educational background, experience, research interests, and publications. 
4. Prior to admission, applicants should be required to identify a research area of interest, as well as a potential research advisor. The aforementioned faculty web-page will help applicants in this effort. Students unable to identify an intended research focus prior to admission should be counseled as to the proper fit between their personal goals for a doctoral degree and the degree programs offered by the college.

5. Upon admission, at their first on-campus meeting, new students should attend an inclusive, focused orientation wherein the entire program process is discussed in detail. A "New Student Orientation" handbook, both online and in print, should be developed to assist in this process.

6. New students should be assigned a faculty or senior student advisor who is readily available to answer questions or concerns the new student might have. It should be understood by all parties that this is an advisory function only, and does not necessarily mean that the faculty member will ultimately serve as the student's dissertation.

7. It should be incumbent on the part of the advisor to maintain periodic contact with new students throughout their first year in the program.

\section{Best Practices for Coursework}

The fourth axial code indicated overwhelming satisfaction with the coursework, but did provide valuable insight from the graduates' perspective. Best practices developed based on their input include:

1. Coursework should be kept current from both a theoretical and an applied perspective.

2. Coursework should better focus on preparing students for the dissertation by embedding a research focus when applicable.

3. Students should be required to take multiple research methodology courses including courses in quantitative methods, qualitative methods, mixed-methods and multivariate statistics.

\section{Best Practices for Beginning and Continuing Through the Dissertation Process}

Issues with the dissertation process were, by far, the most problematic. Graduates described problems with understanding the entire dissertation process, engagement with university personnel upon completion of coursework, the identification of a valid research focus and the identification of a dissertation chair and committee. Suggested best practices include:

1. At the end of each term, a list of students eligible to begin work on their dissertation should be published. In order to establish and maintain connectivity, the previously identified advisor should continue making contact with these students on a monthly basis until the student has identified a dissertation chair. 
2. A handbook clearly outlining all aspects of the dissertation process should be given to all students; consideration should be given to the development of online communities of practice to help maintain connectivity as well as help ensure students are aware of what exactly they should be doing at a given point in time.

3. In addition to the currently available dissertation guide, examples of the component parts of the dissertation should be made available to students. Ideally these examples would include different methodological approaches.

4. In order to maintain connectivity and provide guidance as needed, faculty members are encouraged to suggest regularly scheduled synchronous meetings, be it by phone, online or face-to-face.

5. In order to ensure clarity and understanding between the dissertation chair and student, a synchronous meeting should be scheduled (e.g., online, face-to-face or over the telephone) to discuss feedback for a dissertation submission.

\section{Conclusions}

The purpose of this study was to elucidate factors that graduates of the program felt contributed to their success; their insight has been developed as best practices that should be considered by the college (the combined list of these best practices is included in Appendix B). In moving forward, however, the focus of the interviews quickly shifted to tools and approaches that could have better helped them succeed, thereby being applicable to current and future students. Their comments referring to their own intrinsic motivation further substantiates the work of Terrell (2005b) who reported that the biggest indicator of success in the program is a student's desire to succeed despite perceived barriers to success.

Interestingly, the insight from graduates of the program almost completely mirrors that of students leaving the program prior to graduation (Terrell, Snyder, Dringus and Maddrey, 2012):

...it was found that although students feel that the faculty members are approachable, they are frustrated with the lack of guidance and mentorship while working on their dissertation. The Council of Graduate School's (CGC) Ph.D. Completion Project (www.phdcompletion.org) identifies six areas of promising practices for the development of intervention strategies that can impact doctoral completion rates and attrition patterns. These areas include: student selection and admissions, mentoring and advising, financial support, program environment, research experience, and curricular and administrative practices and procedures. It would be worthwhile to consider intervention strategies specific to mentoring and advising. The CGC identifies the following common themes related to mentoring and advising: improving the support structure between doctoral dissertation chairs, committee, and students; encouraging collective responsibility within the program for the doctoral student's success; providing explicit guidelines and expectations regarding the dissertation process, and developing better conflict resolution strategies (www.phdcompletion.org).

As noted by Lovitts (2001) and others, attrition from doctoral degree programs is inevitable; up to $50 \%$ of students do not finish due to personal, financial or academic reasons. The development and application of policies, procedures and tools based on results of this research, 
however, may help administrators in the college address the additional $10 \%$ to $20 \%$ they have historically experienced.

\section{References}

Bowen, W. \& Rudenstine, N. (1992). In pursuit of the Ph.D. Princeton, NJ: Princeton University Press.

Cohoon, J., Wu, Z., \& Chao, J. (2009). Sexism: Toxic to women's persistence in CSE doctoral programs. Proceedings of the 2009 ACM SIGCSE Conference, 158 - 162.

Ehrenberg, R., Jakubson, G.,Groen, J., So, E., \& Price, J. (2007). Inside the black box of doctoral education: What program characteristics influence doctoral students' attrition and graduation probabilities? Educational Evaluation and Policy Analysis, 29(2), 134 - 150.

Gardner, S.K. (2008). Fitting the mold of graduate school: A qualitative study of socialization in doctoral education. Innovative Higher Education, 33(2), 125 - 138.

Gardner, S.K. (2010). Contrasting the socialization experiences of doctoral students in high- and low-completing departments: A qualitative analysis of disciplinary contexts at one institution. The Journal of Higher Education, 81(1), 61 - 81.

Glaser B. \& Strauss A. (1967) Discovery of grounded theory. Strategies for Qualitative Research. Mill Valley, CA: Sociology Press.

Golde, C.M. (2005). The role of the department and discipline in doctoral student attrition: Lessons from four departments. The Journal of Higher Education, 76(6), 669 - 700.

Groen, J.A., G. Jakubson, R. Ehrenberg, S. Condie \& A. Liu (2008). Program design and student outcomes in graduate education. Economics of Education Review, 27(2) 111-124.

Holder, B. (2007). An investigation of hope, academics, environment, and motivation as predictors of persistence in higher education online programs. The Internet and Higher Education, 10(4), 245 - 260.

Ivankova, N., \& Stick, S. (2007). Students' persistence in a distributed doctoral program in educational leadership in higher education: A mixed methods study. Research in Higher Education, 48(1), 93-135. doi: 10.1007/s11162-006-9025-4.

Kennedy, D., Terrell, S., \& Lohle, M. (2015). A grounded theory of persistence in a limited-residency doctoral program. The Qualitative Report, 20(3).

Lovitts, B. \& Nelson, C. (2000). The hidden crisis in graduate education: Attrition from Ph D programs. Academe, 86(6), $44-51$.

Lovitts, B.E. (2001). Leaving the ivory tower: the causes and consequences of departure from doctoral study. Lanham, UK: Rowman \& Littlefield Publishers, Inc.

Lovitts, B. (2005). Being a good course-taker is not enough: A theoretical perspective on the transition to independent research, Studies in Higher Education, 30(2), 137-154.

Lovitts, B. (2008). The transition to independent research: Who makes it, who doesn't, and why. The Journal of Higher Education, 79(3), 296 - 325.

National Center for Education Statistics. (2000). Percentage distribution of doctoral degree students according to selected student, enrollment, and employment characteristics, by type of degree: 1999-2000. Retrieved May 10, 2006, from http://nces.ed.gov/das/library/tables_listings/show_nedrc.asp?rt=p\&tableID=210.

National Research Council. (1996). The path to the Ph.D.: measuring graduate attrition in the sciences and humanities. Washington, DC: National Academy Press. 
Rovai, A. (2002). Development of an instrument to measure classroom community. The Internet and Higher Education, 5(3), 197-211.

Smallwood, S. (2004, January 16). Doctor dropout. The Chronicle of Higher Education. Retrieved March 18, 2005 from http://chronicle.com/prm/weekly/v50/i19/19a01001.htm

Terrell, S. (2002a). Learning style as a predictor of success in a limited residency doctoral program. Internet in Higher Education, 5(4).

Terrell, S. (2002b). The effect of learning style on doctoral course completion in a Web-based learning environment. The Internet and Higher Education, 5(4), 345 - 352.

Terrell, S. (2005a). A longitudinal investigation of the effect of information perception and focus on attrition in online learning environments. The Internet and Higher Education, 8(3), $213-219$.

Terrell, S. (2005b). Supporting different learning styles in an online learning environment: does it really matter in the long run? Online Journal of Distance Education Administration, $8(2)$.

Terrell, S. (2005c). A longitudinal investigation of the effect of information perception and focus on attrition in online learning environments. Internet in Higher Education, 8(3).

Terrell, S., Snyder, M., Dringus, L. \& Maddrey, E. (2012). A grounded theory of connectivity and persistence in a limited residency doctoral program. The Qualitative Report, 17.

Terrell, S. (2014). The use of experiential learning styles to predict attrition from a limited residency information systems graduate program. The Online Journal of Applied Knowledge Management, 2(1), 1 - 10.

Terrell, S. (2015). Using hemispheric preferences as a predictor of success in a limitedresidency information systems doctoral program. The Online Journal of Applied Knowledge Management, 2(1), 127-133.

U.S. Department of Education, Office of Planning, Evaluation and Policy Development (2009). Evaluation of evidence-based practices in online learning: A meta-analysis and review of online learning studies. Retrieved from http://www2.ed.gov/about/offices/list/opepd/ppss/reports.html

van Ours, J.C. \& Ridder, G. (2003). Fast track or failure: A study of the graduation and dropout rates of Ph.D. students in economics. Economics of Education Review, 22(2), 157 - 166.

\section{Authors' Biographies}

Steve Terrell is a Professor in the College of Engineering and Computing, and the Fischler College of Education, at Nova Southeastern University where he teaches quantitative and qualitative research methods. His Ph.D. is in Higher Education with Masters in Counseling and Business. He is the author of two textbooks focusing on developing dissertation proposals and inferential statistics. Steve has published over 100 journal articles and presentations focusing primarily on student motivation, achievement and attrition at all levels of education. Steve currently serves as chair of the American Educational Research Association's Online Teaching and Learning Special Interest Group and is active in EDUCAUSE, the International Society for Technology in Education and the American Counseling Association.

Mike Lohle has been on the faculty of the Trefz School of Business at the University of Bridgeport since 2013. A certified Project Management Professional (PMP), Mike spent twenty- 
six years in the financial services, insurance, information technology services, pharmaceutical and consumer product industries. He is experienced with all aspects of information technology and his specialty is delivering large business intelligence and analytics solutions for major corporations. Mike has been employed by General Electric, Prudential, Keane, Condor Technology Solutions, PartnerRe, Avon, Gartner, Travelers and WellPoint. Mike's work has published in several peer reviewed journals and presented at multiple conferences. His research interests include project and program management, business intelligence and analytics, and the application of qualitative research methods in business settings.

Donna Kennedy is a Curriculum Director at Indian River Central School District in Philadelphia, NY. Donna received her Ph.D. in Computing Technology in Education from Nova Southeastern University, and is certified in New York State as a School District Administrator and Mathematics Teacher. She possesses over 20 years of experience teaching math and technology in face-to-face, hybrid and online environments at the high-school and collegiate level. 


\section{Appendix A: Survey Instrument}

\section{$\underline{\text { Research Question }}$}

What are the factors and experiences you believe contributed to your persistence in a limited residency doctoral program?

Subsequent questions may include but not be limited to:

1. Why did you choose the limited residency information systems doctoral program?

2. What was your impression of the program when you visited the campus for the first time?

3. What were your experiences during coursework?

4. Did you feel prepared to begin work on your dissertation when you finished your coursework?

5. How did you initiate contact with potential dissertation advisors?

6. What were your experiences while writing your dissertation?

7. What, if anything, could help a student persist in the limited residency doctoral program? 


\section{Appendix B: Best Practices}

1. Applicants should be better screened prior to admission. This may include interviews with faculty members, as well as the use of standardized readiness instruments such as the Graduate Record Exam.

2. Prior to admission, applicants should be counseled as to the differences between the educational experience of a Masters' program and a doctoral program. This should include applicant awareness of the life-style changes, the amount of time that must be dedicated to doctoral study, the reality of attrition, the financial costs, etc.

3. To assist potential applicants in their decision making, the college should provide a page on their web-site for each faculty member that shows detailed information about their educational background, experience, research interests, and publications.

4. Prior to admission, applicants should be required to identify a research area of interest, as well as a potential research advisor. The aforementioned faculty web-page will help applicants in this effort. Students unable to identify an intended research focus prior to admission should be counseled as to the proper fit between their personal goals for a doctoral degree and the degree programs offered by the college.

5. Upon admission, at their first on-campus meeting, new students should attend an inclusive, focused orientation wherein the entire program process is discussed in detail. A "New Student Orientation" handbook, both online and in print, should be developed to assist in this process.

6. New students should be assigned a faculty or senior student advisor who is readily available to answer questions or concerns the new student might have. It should be understood by all parties that this is an advisory function only, and does not necessarily mean that the faculty member will ultimately serve as the student's dissertation.

7. It should be incumbent on the part of the advisor to maintain periodic contact with new students throughout their first year in the program.

8. Coursework should be kept current from both a theoretical and an applied perspective.

9. Coursework should better focus on preparing students for the dissertation by embedding a research focus when applicable.

10. Students should be required to take multiple research methodology courses including courses in quantitative methods, qualitative methods, mixed-methods and multivariate statistics.

11. At the end of each term, a list of students eligible to begin work on their dissertation should be published. In order to establish and maintain connectivity, the previously identified advisor should continue making contact with these students on a monthly basis until the student has identified a dissertation chair.

12. A handbook clearly outlining all aspects of the dissertation process should be given to all students; consideration should be given to the development of online communities of practice to help maintain connectivity as well as ensure students are aware of what exactly they should be doing at a given point in time.

13. In addition to the currently available dissertation guide, examples of the component parts of the dissertation should be made available to students. Ideally these examples would include different methodological approaches. 
14. In order to maintain connectivity and provide guidance as needed, faculty members are encouraged to suggest regularly scheduled synchronous meetings, be it by phone, online or face-to-face.

15. In order to ensure clarity and understanding between the dissertation chair and student, a synchronous meeting should be scheduled (e.g., online, face-to-face or over the telephone) to discuss feedback for a dissertation submission. 